\title{
ETIOPATOGENIA DA UROLITÍASE EM CÃES
}

\section{Paula Costa Ariza ${ }^{1}$, Aline Maria Vasconcelos Lima ${ }^{2}$, Layla Livia de Queiroz ${ }^{3}$, Maria Clorinda Soares Fioravanti ${ }^{2}$}

${ }^{1}$ Doutoranda, Escola de Medicina Veterinária e Zootecnia da Universidade Federal de Goiás, Goiânia, Brasil, e-mail: paula.c.ariza@gmail.com

${ }^{2}$ Doutora, Docente da Escola de Medicina Veterinária e Zootecnia da Universidade Federal de Goiás, Goiânia, Brasil

${ }^{3}$ Doutoranda, Escola de Medicina Veterinária e Zootecnia da Universidade Federal de Goiás, Goiânia, Brasil

\section{Recebido em: 08/09/2015 - Aprovado em: 14/11/2015 - Publicado em: 01/12/2015 DOI: http://dx.doi.org/10.18677/Enciclopedia_Biosfera_2015_155}

\begin{abstract}
RESUMO
A urolitíase é comum na clínica de cães e os casos de recidivas são frequentes. Decorre do desenvolvimento de urólitos no trato urinário e pode levar a alterações graves, como obstruções do fluxo urinário. Diversos fatores, sejam hereditários, congênitos ou adquiridos, podem estar envolvidos no desenvolvimento dos cálculos urinários. Os urólitos que mais frequentemente acometem animais da espécie canina são aqueles formados de estruvita, oxalato de cálcio, urato, cistina, fosfato de cálcio, xantina e sílica. No entanto, cálculos urinários com outras composições como de 2,8diidroxiadenina podem acometer menos frequentemente animais dessa espécie. $O$ conhecimento dos mecanismos que ocasionam a formação e o desenvolvimento dos diferentes tipos de urólito permite a instauração de protocolos de tratamento específicos mais eficientes e que reduzam a possibilidade de ocorrência de recidivas.
\end{abstract}

PALAVRAS-CHAVE: cálculo urinário, canino, patogenia

\section{ETIOPATHOGENESIS OF UROLITHIASIS IN DOGS}

\begin{abstract}
Urolithiasis are common in dogs and recurrences are frequent. This disease results from the development of uroliths in the urinary tract and may lead to important conditions, such as urinary flow obstructions. Many factors, hereditary, congenital or acquired may be involved in the development of urinary calculi. In dogs, the most common urolith compositions are struvite, calcium oxalate, urate, cystine, calcium phosphate, xanthine and silica. However, urinary calculi with different compositions, such as 2,8-dihydroxyadenine may less frequently affect these animals. Knowledge of the mechanisms involved in the formation and growth of each urolith type allow the establishment of specific treatment protocols that are more efficient and reduce the possibility of recurrences.
\end{abstract}

KEYWORDS: canine, pathogenesis, urinary calculus 


\section{INTRODUÇÃO}

A urolitíase é uma enfermidade ocasionada pelo desenvolvimento de concreções policristalinas e ocasionalmente não cristalinas no interior do trato urinário. Decorre de múltiplos fatores que, em conjunto e na presença de urina supersaturada, reduzem a solubilidade de cristais, que precipitam, originando os urólitos (OSBORNE et al., 1995; KOEHLER et al., 2008). Embora casos assintomáticos, nos quais os urólitos são identificados de maneira incidental não sejam incomuns, a presença de urólitos no interior do trato urinário pode ocasionar diversas alterações importantes, desde infecções secundárias a lesões no urotélio ou obstruções no fluxo urinário (OSBORNE et al., 1995).

Alguns animais apresentam predisposição à formação de cálculos urinários. Os estudos sobre genoma canino indicam que mutações podem ocasionar alterações bioquímicas urinárias, responsáveis pela predisposição de algumas raças e linhagens às urolitíase, confirmando o caráter genético da enfermidade (BANNASCH \& HENTHORN, 2008). No entanto, fatores nutricionais, ambientais e metabólicos não relacionados às alterações genéticas também desempenham importante papel na patogenia e evolução da enfermidade (OSBORNE et al., 1995; ULRICH et al., 2008; OKAFOR et al., 2014). As taxas de recorrência são elevadas para a maioria dos urólitos (OSBORNE et al., 1995; OSBORNE et al., 2008).

De modo geral, dentre os vários fatores que possuem relação com o desenvolvimento dos urólitos podem ser citados: infecção urinária, dieta, anomalias hereditárias e congênitas e perda das condições urinárias normais, como alterações no $\mathrm{pH}$ e na densidade (OSBORNE et al., 1995; OSBORNE et al., 2008). Outra ocorrência de muita importância é a redução ou inativação dos inibidores de formação e crescimento dos urólitos, já que em condições normais, mesmo sob concentrações elevadas de cristais litogênicos, não há a formação de aglomerados sólidos no interior do trato urinário, o que indica a importância da ação dos inibidores (OSBORNE et al., 2008; OKAFOR et al., 2014).

Desse modo, é grande a importância da identificação dos indivíduos predispostos à precipitação de cristais urinários, bem como a identificação das alterações que contribuem para a deposição de minerais no trato urinário. Objetivouse com a presente revisão de literatura, descrever as principais causas e os mecanismos envolvidos no desenvolvimento dos cálculos urinários na espécie canina.

\section{ASPECTOS GERAIS SOBRE A UROLITÍASE EM CÃES}

A urolitíase é uma afecção decorrente de alterações metabólicas de ocorrência comum na rotina médica de pequenos animais, chegando a afetar $1,5 \%$ a $3,0 \%$ dos cães admitidos em clínicas veterinárias (OSBORNE et al., 1995). É uma enfermidade que possui altas taxas de recidivas (ULRICH et al., 2008). Se caracteriza pela presença de urólitos em qualquer segmento do trato urinário (OSBORNE et al., 2008) e decorre da precipitação de cristais na urina (SIDOROVA \& GRIGORIEV, 2012). Os urólitos são concreções policristalinas compostas primariamente de cristaloides orgânicos e inorgânicos e menores quantidades de matriz orgânica (OSBORNE et al., 1995).

Quanto à constituição, os cálculos urinários podem ser classificados em simples, quando formados majoritariamente - acima de $70 \%$ - por um único constituinte; mistos, quando há mais de um componente identificado em apenas uma camada, sendo que nenhum componente representa $70 \%$ da constituição do cálculo; e compostos, quando possui camadas justapostas com constituições 
diferentes ou quando se formam sobre material sólido estranho ao trato urinário, como fios de sutura (ULRICH et al., 2008), pois as substâncias sólidas no trato urinário podem servir como local de deposição de cristais (KOEHLER et al., 2008).

As composições químicas mais frequentes dos cálculos urinários em cães são estruvita (fosfato de amônio magnesiano), oxalato de cálcio ( $\mathrm{CaOx}$ ) e uratos (de amônio ou sódio) (OSBORNE et al., 1995; OSBORNE et al., 2008; ROGERS et al., 2011; OKAFOR et al., 2014). Menos frequentemente são encontrados urólitos de fosfato de cálcio, cistina, xantina e sílica (OSBORNE et al., 1995; OSBORNE et al., 2008; ROGERS et al., 2011). Ainda mais raramente podem ser encontrados outros tipos de urólitos, como aqueles formados por 2,8-diidroxiadenina (HOUSTON et al., 2012; FURROW et al., 2013), ou mesmo originários da precipitação de fármacos (KOEHLER et al., 2008). Sinais comuns de urolitíase em cães incluem hematúria, polaciúria, disúria e estrangúria. Obstruções parciais ou totais do fluxo urinário afetam mais os machos e podem levar à hidronefrose (SYME, 2012). A maioria dos urólitos nos cães se desenvolve no trato urinário inferior, sendo que $97 \%$ dos cálculos analisados são provenientes dessa região. Em parte, isso se deve à dificuldade de remoção de urólitos de regiões anteriores ao trato urinário, mas também é relacionada à maior ocorrência de cistólitos devido à posição quadrupedal da espécie e distribuição anatômica do trato urinário, que favorecem a estase urinária na bexiga e a retenção de agregados cristalinos e pequenos urólitos, que nos humanos seriam facilmente eliminados (SYME, 2012).

A interação de diversos fatores predisponentes familiares, congênitos e adquiridos ocasiona a precipitação de cristais na urina que, se não eliminados, podem se aglomerar e levar à formação de cálculos macroscópicos (OSBORNE et al., 2008). Para que sejam identificados os animais e as populações suscetíveis, estabelecido o diagnóstico precoce e elaborada a terapia adequada, é necessária a identificação dos mecanismos envolvidos na deposição dos cristais. Os diversos fatores de risco não são totalmente conhecidos e podem ter ação distinta em cada tipo de urólito (VRABELOVA et al., 2011). As anomalias funcionais ou anatômicas do sistema urinário, como presença de divertículo vesical ou rins em ferradura, estase urinária, infecções do trato urinário, dieta, reduzida ingestão de água, baixo volume urinário, pH urinário, raça, sexo, idade, anomalias metabólicas e até mesmo fatores geográficos e sazonais, podem aumentar as chances de precipitação de cristais litogênicos na urina (NATH et al., 1984; HESS et al., 1997; NEUHAUS et al., 2000; EGGERMANN et al., 2012). O conhecimento da fisipatologia das urolitíases é necessário para reduzir a ocorrência e a recorrência dessa enfermidade (FALLAHZADEH et al., 2012; OKUMURA et al., 2013).

Dependente de diversos eventos químicos e físicos, o desenvolvimento de urólitos é um processo bastante complexo (CARVALHO et al., 2003; OMBRA et al., 2003). Os cristais urinários se precipitam e se dissolvem ou são eliminados sem formar cálculos na urina de indivíduos normais. Porém, esses cristais, quando não eliminados, podem originar urólitos sólidos. A iniciação da formação dos cálculos urinários envolve a excreção aumentada de solutos, a supersaturação urinária e precipitação de cristais, a presença de matriz orgânica, que pode organizar ou modificar o crescimento dos cristais, e a ação de moléculas que inibem ou promovem a formação e deposição de cristais (FINLAYSON, 1978). A excessiva concentração de promotores de cálculos urinários, como oxalato, urato, cálcio, fosfato, amônia e a concentração insuficiente de inibidores, como citrato, pirofosfato e magnésio, são importantes alterações e podem levar ao desenvolvimento de urólitos (SIDOROVA \& GRIGORIEV, 2012). 
A predisposição genética é um fator importante em determinados tipos de cálculos urinários, pois algumas mutações genéticas podem causar precipitação de minerais na urina. A suscetibilidade genética a determinados tipos de urólitos, pode ser compartilhada por cães e humanos (FURROW et al., 2013), como por exemplo na cistinúria causada por mutação do gene SCL3A1 (BRONS et al., 2013) e na excreção de 2,8-diidroxiadenina causada por mutação no gene APRT (FURROW et al., 2013).

\section{FATORES ENVOLVIDOS NO DESENVOLVIMENTO GERAL DAS UROLITÍASES}

\section{FATORES GENÉTICOS}

Os fatores genéticos são muito importantes na formação de cálculos urinários, em conjunto com fatores ambientais (DANPURE, 2000, KIM et al., 2011a ). O sequenciamento do genoma canino se tornou um marco para o estudo, diagnóstico e tratamento de doenças herdadas nessa espécie (BANNASCH \& HENTHORN, 2008).

Embora ocorram diversas situações que influenciam a formação de urólitos, a concentração urinária do metabólito formador do cálculo nas enfermidades calculogênicas, hereditárias ou não, é o evento primordial para o desenvolvimento de concreções urinárias. Portanto, nos casos com origem genética, muitos dos genes mutantes identificados codificam proteínas envolvidas direta ou indiretamente na síntese ou transporte de membrana desses metabólitos (DANPURE, 2000). Alguns tipos de urólitos possuem base genética mais evidente que outros. Alterações primárias no metabolismo levando a concentrações urinárias elevadas de substâncias litogênicas são as causas principais de urolitíase herdada (BANNASCH \& HENTHORN, 2008).

Certas famílias e linhagens de determinadas raças são afetadas por nefropatias hereditárias que representam uma variedade de defeitos de desenvolvimento, metabólicos ou degenerativos. Podem ser citadas, como anormalidades herdadas que podem ocasionar urolitíase, a cistinúria hereditária dos Terriers Irlandeses e o transporte celular defeituoso de urato em Dálmatas (PICUT \& LEWIS, 1987). A determinação das origens genéticas de vários tipos de urolitíase, é dificultada pela natureza multifatorial da enfermidade (DANPURE, 2000). Nos seres humanos, aproximadamente $40 \%$ das urolitíases em crianças ocorrem com a presença de histórico familiar, enquanto que em adultos a ocorrência em conjunto com histórico familiar ocorre de maneira esporádica (EGGERMANN et al., 2012).

O conhecimento genômico de uma enfermidade pode abranger 0 entendimento do modo de herança pelo estudo das famílias afetadas, a descrição da anormalidade gênica ou mesmo o conhecimento da localização da alteração na sequência de DNA responsável pela enfermidade (BANNASCH \& HENTHORN, 2008). Algumas enfermidades possuem origem monogênica, como a hiperoxalúria primária tipo 1 ( $\mathrm{PH} 1)$, e outras, como hipercalciúria idiopática familiar, possuem origens mais complexas. Se as alterações são pouco óbvias e não específicas, como em algumas urolitíases familiares idiopáticas, o padrão real de herdabilidade pode ser mascarado pela sobreposição de influências ambientais, dificultando o isolamento dos genes envolvidos (DANPURE, 2000).

As causas genéticas são mais facilmente identificadas em cálculos menos frequentes, sendo os que ocorrem frequentemente (oxalato de cálcio e estruvita) muitas vezes refratários às análises genéticas. Isso deve-se à identificação facilitada das alterações fisiológicas envolvidas e principalmente dos padrões de herança nas 
urolitíases mais raras (DANPURE, 2000). Raças caninas, por possuírem diversidade genética relativamente baixa, representam uma oportunidade de estudo dos determinantes genéticos das diferentes enfermidades (BRONS et al., 2013). Quando uma raça possui predisposição a um tipo particular de urólitos, provavelmente há algum fator genético primordial envolvido (BANNASCH \& HENTHORN, 2008). Estudar os determinantes genéticos em raças caninas predispostas é uma maneira eficiente de compreender o problema em humanos, pois algumas alterações genéticas são semelhantes nas duas espécies (BRONS et al., 2013).

A frequência do alelo mutante pode variar de zero (se nenhum indivíduo carrega o gene mutante) a um (se todos os indivíduos carregam duas cópias do gene mutante). Quanto maior a frequência de alelos mutantes em uma população, maior a chance de indivíduos dessa população desenvolverem urolitíase (KARMI et al., 2010). A identificação dos genes mutantes envolvidos na formação de cálculos urinários é importante para a formulação de estratégias de manejo clínico do problema, além de permitir que a enfermidade seja redefinida na sua base genética, e não mais apenas pelas alterações bioquímicas (DANPURE, 2000). Embora em casos de urolitíase hereditária a identificação dos genes envolvidos seja importante, muitas vezes a avaliação genética molecular não é realizada e consequentemente as raízes gênicas da enfermidade não são identificadas (BANNASCH \& HENTHORN, 2008).

\section{ALTERAÇÕES CONGÊNITAS, ANATÔMICAS E FUNCIONAIS}

A combinação de anatomia aberrante com infecções urinárias e alterações metabólicas podem predispor a urolitíase (TAN et al., 2013). A eliminação incompleta de urina predispõe a infecções urinárias e à formação e precipitação de cristais (TAN et al., 2013; BECKNELL et al., 2013). A atonia de bexiga, o divertículo vesical e divertículos caliceais predispõem à enfermidade devido à estase urinária (OSBORNE et al., 1995; TAN et al., 2013; BECKNELL et al., 2013). A ectopia ureteral predispõe a infecções e, portanto, à urolitíase (YOON et al., 2012).

Rins em ferradura compreendem má formação congênita renal que ocorre com a fusão dos rins nas porções caudais, originando estrutura em forma semelhante a uma ferradura. Rins em ferradura são limitados pela artéria mesentérica, e se encontram mal posicionados (TAN et al., 2013). Em humanos é uma alteração muito comum que predispõe à formação de urólitos, pois pode levar à estase urinária e a desvios anormais dos ureteres. Rins em ferradura podem estar associados a outras alterações anatômicas, como vascularização aberrante (TAN et al., 2013).

A doença renal policística, caracterizada pela presença de cistos difusos no parênquima renal (KIM et al., 2011b) também é um fator de predisposição à urolitíase. Em humanos, a presença dessa alteração aumenta a chance de ocorrência de cálculos renais em cinco a 10 vezes. Os cistos renais podem obstruir o fluxo urinário, ocasionando estase. A urina de portadores da doença apresenta $\mathrm{pH}$ reduzido e baixos níveis de citrato e magnésio, que são inibidores de urolitíase (TAN et al., 2013).

\section{SUPERSATURAÇÃO URINÁRIA}

Independente de quaisquer outras alterações predisponentes à urolitíase que possam estar presentes, o fator predisponente primordial e necessário para a formação de todos os tipos de cálculos urinários é a supersaturação urinária por substâncias cristalogênicas (OSBORNE et al., 1995; NEUHAUS et al., 2000; 
KOEHLER et al., 2008; ULRICH et al., 2008; BUCKLEY et al., 2011; OKAFOR et al., 2014). Desse modo, a produção de urina concentrada e com altos níveis de minerais calculogênicos é o fator de risco mais importante para o desenvolvimento dos urólitos (BUCKLEY et al., 2011).

A urina pode encontrar-se em estado de subsaturação, saturação, estado metaestável ou de supersaturação. O estado de subsaturação é marcado pela presença de solutos em concentrações menores que o ponto de saturação, ou seja, a baixa concentração dos cristaloides permite sua dissolução. Em situações de subsaturação, os cristais não precipitam ou se agregam e, quando possível, são dissolvidos (BARTGES \& CALLENS, 2015).

Quando ultrapassa o estado de saturação (solução em equilíbrio com soluto não dissolvido), a urina se torna supersaturada. Em baixos níveis de supersaturação, encontra-se em estado metaestável, em que os cristais não precipitam espontaneamente, mas precipitam sob superfícies sólidas; pode haver agregação de cristais; os cristais não são dissolvidos, mas os inibidores podem prevenir a cristalização. Sob altos níveis de supersaturação, os cristais precipitam espontaneamente, podem crescer, se agregar e não são dissolvidos (BARTGES \& CALLENS, 2015).

\section{INFECCÕES BACTERIANAS}

As infecções do trato urinário podem estar presentes em 76,19\% dos cães acometidos pelas urolitíases. As bactérias produtoras de urease predispõem à deposição de cristais de estruvita e fosfato de cálcio. A ureia é um produto do catabolismo dos aminoácidos. Quando hidrolisada pela urease produz grandes quantidades de íons de amônio e carbonato, alcalinizando a urina progressivamente, - que reduz a solubilidade de estruvita e fosfato de cálcio, favorecendo a precipitação (OSBORNE et al., 1995; ULRICH et al., 2008; BECKNELL et al., 2013). Além de ser fator de predisposição à urolitíase, a infecção bacteriana também pode ocorrer secundariamente ao problema (GATORIA et al., 2006; KOEHLER et al., 2008). Nesse caso, a infecção pode ocorrer associada a qualquer tipo de urólito e as bactérias envolvidas podem ou não ser produtoras de urease (GATORIA et al., 2006). A estase urinária, independente da causa, predispõe ao desenvolvimento de infecções urinárias e a formações de urólitos (BECKNELL et al., 2013).

Podem ser citadas como bactérias produtoras de urease que podem ser isoladas do trato urinário dos cães: Staphylococcus coagulase positiva (principalmente S. intermedius) (GATORIA et al., 2006; KOEHLER et al., 2008; SYME, 2012) Proteus spp (KOEHLER et al., 2008; GATORIA et al., 2006); e as ureaplasmas, como Ureaplasma urolyticum (KOEHLER et al., 2008).

Urólitos de estruvita induzidos por infecção urinária muitas vezes possuem em sua composição quantidades variáveis de fosfato de cálcio, cuja deposição também é influenciada por infecções (KOEHLER et al., 2008; GATORIA et al., 2006). As bactérias podem também causar degradação de citrato na urina, resultando em hipocitratúria. O citrato é um importante inibidor de deposição de fosfato (BECKNELL et al., 2013). Para que ocorra a deposição de cristais de fosfato de cálcio em cálculos de estruvita é necessária hipercalciúria concomitante (KOEHLER et al., 2008).

Os urólitos podem predispor o desenvolvimento de infecção urinária devido às lesões uroteliais que podem provocar, ou mesmo pelo impedimento de fluxo urinário e estase urinária (GATORIA et al., 2006). A bactéria Escherichia coli é a espécie mais frequentemente isolada do trato urinário dos cães com urolitíase, 
chegando a estar presente em $43,75 \%$ dos casos e normalmente não é considerada causa do problema, mas consequência (KOEHLER et al., 2008; GATORIA et al., 2006).

A ausência de infecção urinária nas urolitíases pode ser indicativo de origem metabólica ou nutricional para a urolitíase, ou ser decorrente da eliminação natural da infecção pelo organismo do animal, ou mesmo do uso de antibioticoterapia (FALLAHZADEH et al., 2012; GATORIA et al., 2006). Em 23,81\% dos cães com urolitíase e cultura urinária negativa, a realização de cultura da mucosa da bexiga ou mesmo dos urólitos encontram-se positivas (GATORIA et al., 2006).

\section{MATRIZ ORGÂNICA}

A matriz orgânica encontra-se difusamente distribuída nos urólitos (FORTERRE et al., 2006), sendo composta por mistura de proteínas séricas e mucoproteínas (NATH et al., 1984). Pode ou não estar presente nos urólitos, mas acredita-se que, quando presente, seja fator importante no desenvolvimento dos mesmos, atuando em sua modulação (OKUMURA et al., 2013). A matriz pode contribuir para a iniciação da deposição dos cristais e nucleação do urólitos. As proteínas presentes na matriz são muito variáveis, assim como as quantidades (NATH et al., 1984). Algumas proteínas que podem fazer parte da matriz são protrombina, osteoponina e calgranulinas A e B. Cálculos com grandes quantidades de calgranulinas possuem também proteínas expressas por neutrófilos, como mieloperoxidase e lactoferrina (OKUMURA et al., 2013).

O padrão de expressão das proteínas e peptídeos presentes na matriz orgânica dos cálculos urinários é dependente da composição dos mesmos. Cálculos de estruvita possuem maior variedade e quantidade de proteínas da matriz que aqueles de oxalato de cálcio, por exemplo (FORTERRE et al., 2006).

\section{FATORES IATROGÊNICOS}

A urolitíase pode ser decorrente de complicações decorrentes de procedimentos cirúrgicos, como a vesicostomia, devido a ocorrência de contaminação bacteriana. Dessa forma, são favorecidas a deposição principalmente de cristais de estruvita e fosfato de cálcio (PUTTICK \& SEREDA, 2012. BECKNELL et al., 2013). Pacientes que passaram por procedimentos de desvios urinários também possuem grandes chances de infecções urinárias e, portanto, de urolitíases contaminadas. A cateterização por longos períodos e repetitiva também favorece as infecções bacterianas e fornece sítio sólido para a cristalização, predispondo à formação de urólitos contaminados (BECKNELL et al., 2013).

A presença de material de sutura intravesical pode servir de substrato para a formação de biofilme bacteriano (PUTTICK \& SEREDA, 2012; BECKNELL et al., 2013). Além disso, há aumento da taxa de precipitação de cristais sobre quaisquer materiais sólidos no trato urinário. A presença de um local inicial de deposição facilita e estimula o crescimento de urólitos (BECKNELL et al., 2013). O grau de supersaturação necessário para a deposição de cristais na presença de estrutura sólida, podendo esta ser um urólito pré-formado, é menor que aquele necessário à precipitação espontânea dos cristais (FINLAYSON, 1978). A remoção ou dissolução incompleta de urólitos e a infecção bacteriana recorrente resultam em altas taxas de recorrência (BECKNELL et al., 2013).

\section{INIBIDORES DA UROLITÍASE}


O desenvolvimento de urólitos muitas vezes não ocorre mesmo na presença de urina supersaturada com material litogênico. Isso indica que há sistemas que previnem a formação de urólitos (CARVALHO et al., 2003; OKUMURA et al., 2013). Portanto, a ausência, redução ou inativação dos inibidores naturais de nucleação, crescimento e agregação de cristais urinários também são fatores predisponentes à formação dos urólitos (CARVALHO et al., 2003; OMBRA et al., 2003).

Diversas substâncias podem agir como inibidores das urolitíases, sendo que algumas podem apresentar diferentes ações a depender do tipo de cristais (FINLAYSON, 1978). Os inibidores de urolitíases diferem entre si de acordo com os aspectos específicos de cristalização sobre o qual agem. É provável que as várias substâncias inibidoras presentes na urina influenciem de maneira conjunta na formação dos cálculos (FORTERRE et al., 2006). Podem ser citados como inibidores: glicosaminoglicanos (GAGs) (NATH et al., 1984; OMBRA et al., 2003; FINLAYSON, 1978), glicoproteínas, pirofosfato, citrato (FINLAYSON, 1978; OMBRA et al., 2003), osteoponina (FINLAYSON, 1978), nefrocalcina (OMBRA et al., 2003; FINLAYSON, 1978), fetuína-A, magnésio e uroquinase (KIM et al., 2011a).

Os GAGs são cadeias de polissacarídeos decorrentes da degradação de proteoglicanos e são filtrados no glomérulo (OMBRA et al., 2003). O papel dos GAGs nas urolitíases é contraditório e não está bem estabelecido. No entanto, os cães desenvolvedores de urólitos podem possuir GAGs defeituosos ou em concentrações reduzidas na urina (CARVALHO et al., 2003). O mesmo ocorre com seres humanos com urolitíase (OMBRA et al., 2003).

A camada protetora de GAGs que reveste as células uroteliais protege as mesmas contra a aderência de bactérias, facilitando a eliminação durante a micção. Desse modo, a redução desses compostos pode favorecer as infecções urinárias e o desenvolvimento de cálculos urinários contaminados. Por sua vez, a presença de urólitos causa lesões ao urotélio, alterando a camada de GAGs, favorecendo aderência e colonização bacterianas (YOON et al., 2012).

A função das glicoproteínas e proteínas urinárias no desenvolvimento dos urólitos é controversa, pois por vezes são consideradas promotoras e moduladoras do processo, entrando na composição da matriz (FORTERRE et al., 2006). No entanto, também são consideradas inibidoras, podendo ter suas concentrações reduzidas ou estrutura defeituosa naqueles com a enfermidade (CARVALHO et al., 2003).

A proteína de Tamm-Horsfall é sintetizada no ramo ascendente na alça de Henle e nos túbulos contorcidos distais. Liga ésteres de retinol e retinil na urina. A deficiência de proteína de Tamm-Horsfall e aumento de proteína ligante de retinol pode ocorrer em casos de urolitíase e estar envolvidos na patogenia da enfermidade na espécie canina (RAILA et al., 2003). Essa proteína, apesar de inibidora da formação de urólitos, pode estar presente na matriz orgânica dos urólitos em humanos (HESS et al., 1997). No entanto, não é encontrada na matriz dos cálculos em cães (FORTERRE et al., 2006).

Em humanos e ratos, a deficiência de vitamina $A$ é um fator que causa degeneração do epitélio urinário e redução de inibidores das urolitíases, levando a predisposição à enfermidade (NATH et al., 1984). Nos cães, no entanto, essa deficiência não está presente em casos de urolitíase (RAILA et al., 2003). A proteína de Tamm-Horsfall encontra-se em concentrações diminuídas e a proteína ligante de retinol em concentrações aumentadas na urina (e normais no plasma) desses animais, independente do tipo de cálculo formado. A presença de proteína ligante de 
retinol e a redução de proteína de Tamm-Horsfall são marcadores de lesão tubular e doença renal crônica. Não é conhecido se o aumento da excreção urinária de proteína ligante de retinol e redução de proteína de Tamm-Hosfall são causa ou consequência de urolitíase (RAILA et al., 2003).

A uroquinase é uma enzima que degrada a matriz orgânica de urólitos em formação, evitando seu desenvolvimento e crescimento. Está presente na urina, bem como em outros locais, como corrente sanguínea e matriz extracelular (KIM et al., 2011a).

Algumas moléculas de superfície celular também previnem o crescimento de cristais e danos celulares, como a fibronectina (OKUMURA et al., 2013). A osteoponina, a nefrocalcina e o citrato bloqueiam a adesão de cristais de oxalato de cálcio às células. Os níveis de citrato urinário se encontram muito reduzidos em pacientes com urolitíase, especialmente em casos recorrentes (DEFOOR et al., 2008).

A proteína fetuína-A se liga a aglomerados de oxalato e fosfato e de cálcio, evitando sua deposição e pode estar reduzida em pacientes com urolitíase (STEJSKAL et al., 2008). Cães com formação de urólitos eliminam maior quantidade de isoformas de nefrocalcina com menor capacidade inibitória. A presença de urato não altera a capacidade inibitória da nefrocalcina, diferentemente do que ocorre com outros inibidores (CARVALHO et al., 2003). O pirofosfato se une aos cristais, atrasando os processos de nucleação e crescimento. O magnésio atua como inibidor de cálculos de oxalato de cálcio por formar complexo solúvel com o oxalato, reduzindo o oxalato livre que poderia se ligar ao cálcio (NATH et al., 1984). As alterações podem estar presentes de maneira isolada ou em conjunto, podendo vários desses inibidores estar em níveis normais à avaliação (FALLAHZADEH et al., 2012).

Os Dálmatas que desenvolvem urólitos não excretam quantidades significativamente diferentes de urato na urina em relação aos cães saudáveis pertencentes à mesma raça. No entanto, aqueles afetados pela urolitíase excretam quantidades significativamente menores de proteína de Tamm-Horsfall e de GAGs. Há correlação negativa entre concentrações urinárias de ácido úrico e GAGs em Dálmatas com urólitos. Os níveis de citrato não diferem entre os dois grupos, indicando que provavelmente não age como inibidor de urólitos de urato (CARVALHO et al., 2003). Pacientes humanos com cálculos de urato apresentam níveis significativamente maiores do sal na urina (embora todos os seres humanos excretem grandes quantidades de urato) e níveis urinários de GAGs significativamente menores (OMBRA et al., 2003). A excreção menor de GAGs e proteína de Tamm-Horsfall indica que essas substâncias atuam como possíveis inibidores de urólitos de urato (CARVALHO et al., 2003; OMBRA et al., 2003). Também pode ser citada como importante inibidora de cristalização de urato a nefrocalcina que, muitas vezes, encontra-se reduzida na urina de animais desenvolvedores do problema (CARVALHO et al., 2003). Embora em cães a relação ainda não tenha sido provada, em humanos, o sulfato de condroitina reduz a adesão do ácido úrico às células, o que poderia levar à deposição de cristais e à urolitíase (OMBRA et al., 2003). 


\section{FATORES ENVOLVIDOS NO DESENVOLVIMENTO DE URÓLITOS ESPECÍFICOS}

\section{URÓLITOS DE ESTRUVITA}

Os urólitos de estruvita (fosfato magnesiano de amônio) ocorrem muito frequentemente em cães, sendo historicamente o tipo mais frequente na espécie (OSBORNE et al., 2008; SYME, 2012). Em análises realizadas em 55 urólitos provenientes de cães do município de Goiânia - GO, Brasil, a estruvita foi encontrada, de maneira isolada ou associada a outros compostos, em $92,3 \%$ dos mesmos. O componente mais frequentemente associado à estruvita foi o fosfato de cálcio (ARIZA, 2014).

Os urólitos se desenvolvem em urina alcalina supersaturada por fosfato, amônio e magnésio (KOEHLER et al., 2008). Um dos principais fatores de predisposição à urolitíase por estruvita é a infecção urinária por bactérias produtoras de urease (NATH et al., 1984; RAILA et al., 2003; GATORIA et al., 2006; DEFOOR et al., 2008; KOEHLER et al., 2008; ULRICH et al., 2008; SYME, 2012; BECKNELL et al., 2013). Havendo esse tipo de infecção bacteriana, associada à presença de magnésio e fosfato urinários (naturais na urina canina), as chances de ocorrência de cálculos de estruvita são muito aumentadas. A urease, em presença de água, hidrolisa a ureia, produzindo amônia e carbonato. A amônia se combina a íons hidrogênio e forma íons amônio. A hidrólise da ureia também alcaliniza o meio, reduzindo a solubilidade dos cristais de fosfato magnesiano de amônio (OSBORNE et al., 1995). Urólitos de estruvita podem se desenvolver sem presença de infecção bacteriana, mas essa ocorrência é muito menos frequente (OSBORNE et al., 2008; ULRICH et al., 2008).

Como as fêmeas estão mais suscetíveis a infecções urinárias que os machos devido às diferenças anatômicas no trato urinário, essas apresentam mais esse tipo de urolitíase (SYME, 2012). Cálculos de estruvita chegam a representar aproximademente $85 \%$ dos urólitos de fêmeas caninas (KOEHLER et al., 2008).

As raças mais afetadas por esse tipo de urólito são Schnauzer Miniatura, Shih Tzu, Yorkshire Terrier, Pug, Retriever do Labrador e Dachshund. A idade comum de desenvolvimento é entre dois e nove anos de idade (KOEHLER et al., 2008). São outros fatores de risco para a urolitíase de estruvita: inflamação do trato urinário, aumento de amônia urinária (amônio é a forma protonada da amônia), aumento de mucoproteínas que podem formar a matriz, redução dos inibidores pirofosfato e citrato, que inibem principalmente cristalização de fosfato de cálcio, frequentemente associado à urolitíase por estruvita (NATH et al., 1984).

Raças com machos predispostos a esse tipo de cálculo, que é mais frequente nas fêmeas, como Cocker Spaniel, Springer Spaniel e Retriever do Labrador, indicam que pode haver um loco de suscetibilidade para urólitos por estruvita. No entanto, ainda não foram identificadas as alterações genéticas que provocam precipitação de estruvita na urina (BANNASCH \& HENTHORN, 2008). Cálculos de estruvita são passíveis de dissolução por meio de tratamento nutricional ou medicamentoso (SYME, 2012).

\section{URÓLITOS DE OXALATO DE CÁLCIO}

Embora tenham sido raros em cães no passado, a ocorrência de urólitos de oxalato de cálcio aumentou em várias regiões geográficas, como Estados Unidos e países da Europa, passando a ser frequentes nessas localidades (OSBORNE et al., 2008; ROGERS et al., 2011; OKAFOR et al., 2014). Uma explicação possível é o 
uso de dietas que, ao reduzir a ocorrência de urólitos de estruvita, aumenta a dos de oxalato, pois muitos dos fatores de prevenção de cálculos de estruvita são fatores de indução de cálculos de oxalato de cálcio (OKAFOR et al., 2014; SYME, 2012). Alterações na popularidade das raças também pode ter influenciado essa mudança (SYME, 2012). No entanto, a frequência desses urólitos pode ser variável. No Município de Goiânia, por exemplo, de 55 cálculos urinários caninos analisados, apenas 9,1\% continham oxalato de cálcio em sua composição (ARIZA, 2014).

Os cães do sexo masculino estão mais predispostos a urólitos de oxalato de cálcio chegando a representar $70 \%$ dos animais afetados. À exceção de cálculos de estruvita, todos os outros cálculos afetam mais os machos, provavelmente porque as fêmeas, por possuírem uretra mais larga e curta, podem eliminar mais facilmente os cálculos pequenos (KOEHLER et al., 2008). Raças pequenas como Schnauzer Miniatura, Yorkshiere Terrier, Bichon Frisé (KOEHLER et al., 2008; OKAFOR et al., 2014). Poodle Miniatura (OKAFOR et al., 2014), Lhasa Apso, Lulu da Pomerânia e Shih Tzu são as mais comumente afetadas (SYME, 2012). As chances de desenvolver esse tipo de cálculo crescem com a idade até os sete anos (OKAFOR et al., 2014). As taxas de recorrência de urólitos de oxalato de cálcio são muito altas, podendo atingir $36 \%$ em um ano, $42 \%$ após dois anos e $48 \%$ após três anos (KOEHLER et al., 2008).

A etiopatogenia da urolitíase por oxalato de cálcio não está completamente estabelecida, pois depende de diversos fatores de risco (ROBERTSON et al., 2002). Podem ser citados: altas concentrações urinárias de oxalato, cálcio e de promotores de cristalização desses íons (como o urato); e baixas concentrações de inibidores (como o citrato e GAGs), urina ácida e redução de volume urinário. A maioria dessas alterações possui origem genética ou ambiental (NATH et al., 1984; DANPURE, 2000; FALLAHZADEH et al., 2012; FURROW et al., 2015). O hiperparatireoidismo, por levar a reabsorção óssea e absorção intestinal aumentada de cálcio, ocasiona hipercalciúria, predispondo à urolitíase com cálcio (NATH et al., 1984; TAN et al., 2013).

\section{Alterações metabólicas}

Em seres humanos, que possuem a urina naturalmente supersaturada por oxalato de cálcio, até mesmo pequenas perturbações podem causar alterações de homeostasia, levando à precipitação de cristais (DANPURE, 2000; THAMILSEVAN et al., 2014). Nessa espécie, urolitíase por oxalato de cálcio é o tipo mais frequente e os níveis de supersaturação urinária por oxalato de cálcio em pacientes com urolitíase recorrente são maiores que nos pacientes no primeiro episódio de urolitíase (DEFOOR et al., 2008).

A urina dos cães geralmente não possui níveis de oxalato de cálcio que atinjam a supersaturação (OSBORNE et al., 1995). No entanto, podem ser encontradas concentrações urinárias de cálcio em cães saudáveis tão altas como em cães com urólitos de oxalato de cálcio, o que caracteriza as variações que podem ocorrer na excreção de oxalato de cálcio (ROBERTSON et al., 2002).

A hipercalciúria idiopática está presente sob concentrações normais de cálcio sérico (RAILA et al., 2003). Cálculos de oxalato de cálcio são frequentemente relacionados a esse tipo de hipercalciúria, e muitas vezes a etiologia permanece indeterminada (NEUHAUS et al., 2000). Três alterações na homeostasia do cálcio são possíveis explicações para hipercalciúria idiopática em cães com urólitos: aumento na absorção intestinal, aumento na reabsorção óssea e redução na 
reabsorção renal (FURROW et al., 2015). Em cães normais, cerca de $98 \%$ do cálcio secretado é reabsorvido nos rins (NATH et al., 1984).

Em animais da espécie canina com esse tipo de urólito, o cálcio urinário normalmente encontra-se em concentrações elevadas (FURROW et al., 2015; DIJCKER et al., 2015). No entanto, o oxalato não se encontra aumentado na mesma proporção. A relação cálcio:oxalato é, em média, 3,92 vezes maior que a relação em cães saudáveis (DIJCKER et al., 2015). A concentração de oxalato urinário pode inclusive estar em níveis normais (FURROW et al., 2015). Dessa forma, em cães, a hipercalciúria, mais que a hiperoxalúria, parece ser fator predisponente à formação de urólitos de oxalato de cálcio, no entanto, em $71 \%$ dos animais, as concentrações de cálcio e oxalato encontram-se dentro dos parâmetros normais, o que indica a presença de outros fatores predisponentes (DIJCKER et al., 2015).

Já nos humanos, embora o aumento na excreção urinária de cálcio também seja importante, a hiperoxalúria é um dos principais fatores de risco de ocorrência de urólitos por oxalato de cálcio (BODAKHE et al., 2013). Pequenos aumentos na concentração urinária de oxalato já exercem efeito litogênico importante. O mesmo não ocorre com o cálcio (HESS et al., 1997). e, embora a hipercalciúra seja uma anormalidade comum em pacientes humanos desenvolvedores de urólitos de oxalato de cálcio, ela possui papel menos importante que a hiperoxalúria, que é mais eficiente em aumentar a saturação de oxalato de cálcio (NATH et al., 1984).

O aumento da excreção de oxalato pode não apresentar causas evidentes, podendo ocorrer em pacientes sem alterações laboratoriais e origens metabólicas claras; sendo assim caracterizada hiperoxalúria idiopática (NEUHAUS et al., 2000; FALLAHZADEH et al., 2012).

O oxalato tem ação citotóxica oxidativa nas células dos túbulos renais e do urotélio de outras regiões do trato urinário que facilitam a adesão de cristais (BODAKHE et al., 2013). Lesões celulares oxidativas em células do trato urinário, podem portanto, induzir à deposição de cristais de oxalato de cálcio. Em humanos, as lesões oxidativas podem ocorrer mesmo sob concentrações fisiológicas de oxalato, se as quantidades de antioxidantes endógenos estiverem reduzidas, ou se houver a depleção dos mesmos, o que também pode ocorrer devido à ação do próprio oxalato (THAMILSEVAN et al., 2014). À histologia podem ser identificados depósitos cristalinos nos túbulos renais e necrose difusa do epitélio tubular, o que confirma a lesão renal (BODAKHE et al., 2013).

A identificação e a classificação do tipo de oxalúria é difícil (NEUHAUS et al., 2000). A hiperoxalúria primária pode ocorrer devido a problemas genéticos herdados relacionados ao metabolismo do glioxilato, que leva a excreção aumentada de ácido oxálico (NATH et al., 1984) ou devido a alterações hepáticas. Esse tipo se apresenta com elevação persistente de oxalato urinário e níveis normais ou reduzidos de cálcio urinário e ocorre em menos da metade dos pacientes humanos. A hiperoxalúria secundária pode ter origem entérica ou nutricional. Ocorre também aumento da excreção de oxalato sem qualquer causa identificada (NEUHAUS et al., 2000).

Ainda no homem, a hiperoxalúria secundária entérica é consequência da absorção exagerada do oxalato, que pode ocorrer em processos inflamatórios intestinais (NATH et al., 1984; NEUHAUS et al., 2000; SYME, 2012). O aumento dos níveis urinários de oxalato nos casos de urólitos por hiperoxalúria secundária entérica ocorre de forma inconsistente e os níveis urinários de cálcio podem estar normais ou aumentados. Hipocitratúria encontra-se presente. A creatinina sérica 
pode ou não estar aumentada. A hiperoxalúria nutricional ocorre com a ingestão de alimentos ricos em oxalato ou glicolato, ou muito pobres em cálcio, ou com a redução de bactérias intestinais degradadoras de oxalato e se associa a taxas urinárias de oxalato intermitentemente aumentadas (NEUHAUS et al., 2000).

Em cães e humanos o urato pode influenciar na etiologia de cálculos contendo cálcio em sua composição. Dessa forma, aumento na excreção urinária de urato pode predispor não apenas a cálculos de urato, mas também àqueles formados por oxalato de cálcio (PAK et al., 1976). Em caso de hiperuricosúria, os cristais de urato podem se precipitar e desenvolver um núcleo sólido, formando um sítio de deposição de cristais de oxalato de cálcio em sua composição, caracterizando nucleação heterogênea (quando o cálculo se desenvolve pela precipitação dos cristais sobre material sólido pré-existente) (PAK et al., 1976; KOEHLER et al., 2008; ULRICH et al., 2008). O urato também pode absorver GAGs inibidores da agregação de cristais de oxalato de cálcio, promovendo a agregação dos mesmos (PAK et al., 1976). Dessa forma, agregados de oxalato de cálcio se encontram mais proeminentes em amostras de urina contendo sais de urato que em urina livre de urato (PAK et al., 1976).

Urólitos de oxalato de cálcio possuem concentrações reduzidas de proteínas, sendo que algumas podem estar envolvidas no desenvolvimento ou na prevenção das urolitíase (OKUMURA et al., 2013). As proteínas de Tamm-Horsfall (em humanos), protrombina, calgranulinas A e B, osteoponina e mieloperoxidase podem compor a matriz orgânica desses cálculos, caso a mesma esteja presente (OKUMURA et al., 2013).

\section{Alterações hereditárias}

A urolitíase por oxalato de cálcio tem ligação com diversos genes diferentes em seres humanos e alterações nos genes codificador de alaninoglioxilato transferase (AGT) (KIM et al., 2011a; DANPURE, 2000), codificador de canal de cloreto (CLCN5) (DANPURE, 2000) e interleucina-1 $\beta$ (IL-1 $\beta$ ) e receptor sensor do cálcio (CaSR) - regulador da homeostasia celular de cálcio - relacionadas a hipercalciúria e do gene uroquinase - relacionada à formação de cálculos de oxalato de cálcio(KIM et al., 2011a) -foram identificadas nesta espécie. No entanto, mutações específicas ainda não foram encontradas nos cães (PICUT \& LEWIS, 1987).

\section{URÓLITOS DE CISTINA}

Animais e humanos acometidos por cistinúria persistente podem desenvolver urólitos, passíveis de dissolução mediante tratamento médico (SYME, 2012), formados por este aminoácido (BANNASCH \& HENTHORN, 2008; KOEHLER et al., 2008; BRONS et al., 2013). Nos cães, os cálculos de cistina são raros (OSBORNE et al., 2008; ROGERS et al., 2011) podendo representar $1,1 \%$ dos cálculos urinários desenvolvidos por essa espécie (SYME, 2012). A idade média de desenvolvimento dos mesmos está entre 4,8 e 5,6 anos (BANNASCH \& HENTHORN, 2008). Os machos são mais afetados e representam de $94 \%$ a $98 \%$ dos casos (KOEHLER et al., 2008; SYME, 2012). O problema pode causado por alterações hereditárias (BRONS et al., 2013).

\section{Alterações metabólicas}

A cistinúria é uma desordem do transporte transmembrana do aminoácido não essencial cistina e de aminoácidos dibásicos lisina, ornitina e arginina, que 
ocorre nas células dos túbulos renais e intestinais e leva à eliminação aumentada desses aminoácidos na urina (NATH et al., 1984; SANDERSON et al., 2001; FORTERRE et al., 2006; BANNASCH \& HENTHORN, 2008; CHILLARÓN et al., 2010; PUTTICK \& SEREDA, 2012; SYME, 2012). Em condições normais, esses aminoácidos seriam reabsorvidos nos túbulos (DANPURE, 2000). Apenas a cistina possui baixa solubilidade, especialmente em urina ácida ou neutra e pequenas concentrações da mesma excedem a saturação urinária (NATH et al., 1984' DANPURE, 2000; BANNASCH \& HENTHORN, 2008; CHILLARÓN et al., 2010; SYME, 2012). A absorção reduzida no intestino não leva a estados de deficiência nutricional desses aminoácidos não essenciais (BANNASCH \& HENTHORN, 2008). A cistinúria foi um dos primeiros erros de metabolismo a ser identificado em diversas raças caninas (BRONS et al., 2013).

Muitas vezes, os cães com cistinúria apresentam aumento na excreção urinária de diversos aminoácidos; até mesmo não dibásicos (HOPPE et al., 1993b), como a carnitina (SANDERSON et al., 2001), sendo que $46 \%$ desses animais podem apresentar excreção aumentada de cinco ou mais aminoácidos. Cistinúria isolada ou a excreção de aminoácidos dibásicos de maneira isolada são raros (HOPPE et al., 1993b).

Cães com cistinúria, diferentemente de humanos, possuem excreção renal aumentada do aminoácido carnitina, o que pode ocasionar redução plasmática desse aminoácido. Porém, a excreção urinária de taurina não se faz presente, assim como nos humanos. Como a cistina é um aminoácido precursor da síntese de taurina, no entanto, a excreção aumentada de cistina pode afetar a síntese de taurina. Portanto, cães cistinúricos devem ser monitorados quanto à deficiência de carnitina e taurina (SANDERSON et al., 2001). As excreções de treonina, ácido glutâmico, glutamina, cisteína, cistationina, arginina, 1-metil-histidina e 3-metilhistidina também podem estar aumentadas na urina de cães com cistinúria (HOPPE et al., 1993b).

Nem todos os cães com cistinúria desenvolvem urólitos, porém altas concentrações de cistina na urina são fator predisponente à sua ocorrência (HOPPE et al., 1993b). A cistinúria com formação de urólitos é uma enfermidade complexa na qual outros fatores, que não apenas a excreção da cistina, devem ser considerados (HOPPE et al., 1993a; HOPPE et al., 1993b). Cães cistinúricos possuem diurese reduzida, quando comparados a animais saudáveis, e excretam quantidades variáveis de cistina na urina ao longo do tempo, o que dificulta a identificação de animais com chances de desenvolver urólitos desse aminoácido. Pode haver inclusive sobreposição das concentrações de cistina urinária entre cães clinicamente normais e aqueles com urólitos (HOPPE et al., 1993a). Na metade dos casos de urolitíase por cistina, cristais urinários de cistina não são visualizados. Em um mesmo cão com urólitos de cistina, a excreção desse aminoácido varia do valor normal até 100 vezes mais (BANNASCH \& HENTHORN, 2008).

\section{Alterações hereditárias}

Os genes que codificam as subunidades do sistema de transporte dos aminoácidos são SLC3A1 e SLC7A9. No entanto, a etiologia gênica da cistinúria hereditária e os modos de herdabilidade da enfermidade são múltiplos. Os loci mutantes identificados nesses dois genes em animais com cistinúria também são vários. Foram identificadas mutação autossômica recessiva no gene SLC3A1 e mutações autossômicas incompletamente recessivas e dominantes nos genes SLC3A1 e SLC7A9 (HENTHORN et al., 2000). 
A cistinúria hereditária é, em humanos, a alteração genética causadora de urolitíases mais comum, com uma prevalência de 1:7.000 (DANPURE, 2000). Essa alteração pode ser classificada em tipo 1 e não tipo 1 . A cistinúria tipo 1 é autossômica recessiva, com mutação no gene SLC3A1 enquanto a não tipo 1 é incompletamente recessiva (os heterozigotos também excretam quantidades aumentadas de cistina e podem desenvolver urólitos) com mutação no gene SLC7A9 (DANPURE, 2000; SYME, 2012; EGGERMANN et al., 2012; BRONS et al., 2013). Os pacientes podem desenvolver mais de um tipo de cistinúria de maneira concomitante (DANPURE, 2000). Ambos genes codificam transportadores de aminoácidos $b^{0+}$, que são expressados na membrana de células epiteliais do túbulo proximal e intestino delgado (CHILLARÓN et al., 2010; SYME, 2012).

Animais com cistinúria tipo 1 podem desenvolver urólitos de cistina quando jovens ou adultos, enquanto geralmente são cães machos maduros e inteiros que desenvolvem cistinúria não tipo 1, o que indica possível dependência de testosterona (BRONS et al., 2013). Em humanos, mais de 95\% dos carreadores de duas mutações nos genes SLC3A1 ou SLC7A9 desenvolverão urolitíase durante a vida, porém é difícil prever a idade de ocorrência da alteração (EGGERMANN et al., 2012).

A cistinúria canina é geneticamente heterogênea (BANNASCH \& HENTHORN, 2008). A mutação de SLC3A1 foi identificada em cães das raças Terra Nova e Retriever do Labrador com aumento de excreção urinária de cistina (BRONS et al., 2013; BANNASCH \& HENTHORN, 2008). Portanto essas raças apresentam cistinúria tipo 1. Esses cães, machos ou fêmeas, desenvolvem urólitos por cistina ainda jovens (apenas alguns meses de idade) (BANNASCH \& HENTHORN, 2008; SYME, 2012) e as concentrações de cistina e aminoácidos dibásicos urinária nos animais afetados de ambas as raças são cerca de três vezes mais elevados que em animais de outras raças (BANNASCH \& HENTHORN, 2008). Em raças diferentes, não foram identificadas mutações no gene SLC3A1. Mutações no gene SLC7A9 ainda não foram identificadas nos cães (BANNASCH \& HENTHORN, 2008). Outras raças podem ser afetadas por cistinúria (BANNASCH \& HENTHORN, 2008) dentre elas: Bulldog Inglês, Staffordshire Bull Terrier, Mastiff, Dachshund e Chihuahua (KOEHLER et al., 2008).

A cistinúria hereditária do Terrier Irlandês é caracterizada por defeito de transporte tubular da cistina, sendo que as altas taxas de excreção do aminoácido na urina encontram-se presentes sob concentrações plasmáticas normais do mesmo. Nessa raça o desenvolvimento de cálculos de cistina pode ocorrer em animais com três a cinco anos de idade. Não foram identificados o gene nem o padrão de herança envolvidos (PICUT \& LEWIS, 1987).

\section{URÓLITOS DE FOSFATO DE CÁLCIO}

Os urólitos simples de fosfato de cálcio são muito raros nos cães. No entanto, por vezes, este componente encontra-se na composição de cálculos urinários, associados a outros compostos, especialmente à estruvita indicando provável ocorrência de infecção urinária (OSBORNE et al., 2008; ULRICH et al., 2008; VRABELOVA et al., 2012).

As raças mais afetadas são Bichon Frisé, Poodle Miniatura, Lulu da Pomerânia, Pug Shih Tzu e Yorkshire Terrier. Os machos são mais afetados, representando pouco mais de $53 \%$ dos casos e as idades mais comuns de desenvolvimento desse urólitos é menor que um ano e entre seis e 10 anos (KOEHLER et al., 2008). No Município de Goiânia, em estudo realizado com urólitos 
caninos, $58,2 \%$ dos urólitos apresentaram este componente em sua estrutura, sendo que em todos o fosfato de cálcio encontrava-se associado à estruvita (ARIZA, 2014).

Fatores predisponentes que levam à supersaturação urinária por fosfato de cálcio contribuem para o desenvolvimento de urólitos dessa composição. Podem ser citadas situações que aumentam a excreção de cálcio, como o hiperparatireoidismo primário, intoxicação por vitamina $D$, ingestão excessiva de cálcio e insuficiência da adrenal (OSBORNE et al., 1995; YOON et al., 2012). Cálculos de fosfato de cálcio muitas vezes ocorrem associados a desordens hipercalcêmicas, mas também podem estar associados a hipercalciúria idiopática (YOON et al., 2012).

Algumas situações que levam à urolitíase por estruvita aumentam também as chances de ocorrência de urólitos de fosfato de cálcio, como infecções urinárias por bactérias produtoras de urease e urina alcalina (KOEHLER et al., 2008; YOON et al., 2012). O fosfato de cálcio muitas vezes é encontrado associado a estruvita em cálculos compostos e mistos. A maior parte dos urólitos formados por mais de um tipo mineral é formada por esses dois compostos (VRABELOVA et al., 2012).

A proteína hepática fetuína-A (inibidora da calcificação ectópica) é inibidora da precipitação de cristais em soluções supersaturadas por fosfato e íons cálcio. A concentração urinária de fetuína-A encontra-se reduzida em pacientes humanos com urolitíase. Essa proteína se liga a aglomerados de fosfato e de cálcio, evitando sua deposição (STEJSKAL et al., 2008).

\section{URÓLITOS DE URATO}

Cálculos de urato podem ser formados em cães de quaisquer raças, mas um terço desse tipo de cálculos ocorre na raça Dálmata, sendo os machos mais afetados (PICUT \& LEWIS, 1987). Urólitos de urato estão associados à formação de urina ácida, consumo de dietas ricas em proteína e a algumas disfunções hepáticas (ULRICH et al., 2008). Ocorre devido a metabolismo incompleto das purinas (BANNASCH \& HENTHORN, 2008).

Urólitos de urato são relativamente comuns, podendo representar por volta de $5 \%$ de todos cálculos urinários desenvolvidos por cães, a depender da região geográfica (SYME, 2012). No Município de Goiânia, o urato foi identificado em $7,3 \%$ de 55 cálculos caninos analisados (ARIZA, 2014).

\section{Alterações metabólicas}

A hiperuricosúria, que é o aumento anormal da concentração de ácido úrico/ urato na urina, é fator de risco primordial para ocorrência de urolitíase por urato (CARVALHO et al., 2003; OMBRA et al., 2003; BANNASCH \& HENTHORN, 2008; KARMI et al., 2010). Todos os cães da raça Dálmata são naturalmente hiperuricosúricos. A concentração de urato na urina de cães é considerada normal em concentrações abaixo de 9,5mg/dL (BANNASCH \& HENTHORN, 2008).

$\mathrm{O}$ ácido úrico é produto do metabolismo incompleto das purinas. $A$ hipoxantina é convertida em xantina pela enzima xantina oxidase. A mesma enzima converte xantina em ácido úrico, que, por sua vez, é convertido em alantoína pela ação da enzima ácido úrico oxidase (uricase) (SYME, 2012; BANNASCH \& HENTHORN, 2008). A enzima uricase tem sua ação no fígado, no interior dos hepatócitos. A alantoína é muito solúvel na urina, diferentemente do urato, e é o produto final do metabolismo das purinas na maioria dos mamíferos (BANNASCH \& HENTHORN, 2008). 
Quantidades reduzidas de uricase levam a hiperuricemia e hiperuricosúria, predispondo à formação de cálculos urinários de urato (PAK et al., 1976; BANNASCH \& HENTHORN, 2008; SYME, 2012), que representam cerca de $5 \%$ de todos os cálculos urinários desenvolvidos nos cães (SYME, 2012).

Primatas não apresentam a enzima uricase (SYME, 2012) e possuem naturalmente altas concentrações, sérica e urinária, de urato. Os seres humanos excretam níveis de ácido úrico três vezes maiores que os cães (BANNASCH \& HENTHORN, 2008). Dessa forma, a espécie humana é predisposta ao acúmulo de ácido úrico nas articulações (gota) e à urolitíase por urato (SYME, 2012).

Nos cães de raças diferentes da Dálmata, o aumento na excreção de ácido úrico pode ocorrer devido a enfermidades como desvios portossistêmicos e doença hepática grave, pois a ação e produção da enzima uricase ocorrem exclusivamente no fígado (BANNASCH \& HENTHORN, 2008; KOEHLER et al., 2008; SYME, 2012). Cães com urólitos de urato normalmente possuem urina ácida a neutra (KOEHLER et al., 2008).

\section{Alterações hereditárias}

A atividade reduzida da enzima uricase e a excreção renal aumentada de urato podem ser ocasionadas por alteração genética resultando em fluxo secretório excessivo de urato na urina, o que favorece a formação de cálculos urinários (PICUT \& LEWIS, 1987). A hiperuricosúria hereditária é uma alteração autossômica recessiva e os indivíduos devem ter duas cópias da mutação, para desenvolver a condição (KARMl et al., 2010). Mutações que provocam hiperuricosúria foram identificadas em raças caninas como Dálmata (BANNASCH \& HENTHORN, 2008; SYME, 2012), American Staffordshire Terrier, Pastor Australiano, Pastor Alemão, Schnauzer Gigante, Parson Russel Terrier, Retriever do Labrador, Munsterlander, Lulu da Pomerânia, Boerboel e Weimaraner (KARMI et al., 2010). O gene SLC2A9 foi identificado como sendo codificador de transportador de urato e sua mutação está associada à hiperuricosúria nos cães e em humanos (SYME, 2012).

O defeito tubular hereditário do metabolismo do urato nos cães da raça Dálmata aumenta a propensão de animais da raça a desenvolverem urolitíase (PICUT \& LEWIS, 1987). Todos os Dálmatas são potenciais formadores de urólitos de urato por eliminarem elevadas taxas da substância na urina (CARVALHO et al., 2003). A urolitíase por urato pode acometer cerca de $26,5 \%$ a $34 \%$ dos cães Dálmatas machos (BANNASCH \& HENTHORN, 2008). A prevalência da urolitíase por urato na raça como um todo pode chegar a 19,5\% (HOPPE et al., 1993a). Nesses cães, $96 \%$ dos cálculos desenvolvidos são formados por urato e esse tipo de cálculo urinário possui nível de recorrência de até 33\% (KOEHLER et al., 2008).

A hiperuricosúria em Dálmatas ocorre devido à impermeabilidade parcial das membranas celulares, especialmente hepáticas e renais, ao ácido úrico e à sua reduzida reabsorção nos túbulos proximais e não devido à redução de níveis séricos da enzima uricase, como em cães de outras raças (PICUT \& LEWIS, 1987; BANNASCH \& HENTHORN, 2008; SYME, 2012). Como o transporte de ácido úrico nas membranas celulares é defeituoso, há a inacessibilidade da uricase ao ácido úrico, pois o mesmo não adentra os hepatócitos, onde há atividade enzimática (CARVALHO et al., 2003). Nos Dálmatas, o principal produto do metabolismo das purinas não é a alantoína (solúvel na urina) e sim o ácido úrico (BANNASCH et al., 2004). Aproximadamente $60 \%$ a $70 \%$ da xantina é convertida nesse ácido, o que eleva sua concentração sérica e principalmente urinária (CARVALHO et al., 2003). Como nos túbulos renais também há marcada impermeabilidade das membranas 
celulares ao ácido úrico (filtrado no glomérulo e reabsorvido nos túbulos proximais), a reabsorção do mesmo também é prejudicada. Essa alteração explica porque nos Dálmatas, a concentração urinária de urato é muito aumentada, enquanto que a concentração sérica possui apenas pequeno aumento (BANNASCH \& HENTHORN, 2008; SYME, 2012).

As concentrações séricas de urato nos Dálmatas (ácido úrico sérico de $1,3 \mathrm{md} / \mathrm{dL}$ e urinário por volta de $37,8 \mathrm{mg} / \mathrm{dL}$ ), embora um pouco mais altas que a de outros cães (ácido úrico sérico de $0,5 \mathrm{md} / \mathrm{dL}$ e urinário por volta de $9,5 \mathrm{mg} / \mathrm{dL}$ ), não são tão elevadas quanto nos seres humanos (ácido úrico sérico de 5 a $6 \mathrm{md} / \mathrm{dL}$ e urinário por volta de $33,3 \mathrm{mg} / \mathrm{dL}$ ), o que explica o não desenvolvimento de gota nesses cães. No entanto, nota-se que a concentração de urato urinário é muito elevada (SYME, 2012).

A impermeabilidade de membrana a ácido úrico ocorre devido à mutação do gene SLC2A9 (BIBERT et al., 2009), que ocasiona alterações nos aminoácidos da proteína transportadora de urato, codificada por esse gene (BIBERT et al., 2009). Todos os indivíduos da raça Dálmata possuem homozigose para a condição que leva ao metabolismo errôneo do ácido úrico e é de origem genética autossômica recessiva (CARVALHO et al., 2003; SYME, 2012). A mutação ocasiona concentrações plasmáticas de ácido úrico mais altas que em cães normais e excreção de urato marcadamente elevada (CARVALHO et al., 2003).

Os urólitos de urato nos Dálmatas geralmente se desenvolvem pela primeira vez em animais entre três e seis anos de idade, especialmente na bexiga e uretra, predispondo à ocorrência de cistite e uretrite (PICUT \& LEWIS, 1987). Em cães dessa raça, apenas o sexo foi identificado como variável que contribui significativamente para a ocorrência de urolitíase. Embora todos os cães dessa raça excretem grandes quantidades de urato na urina, nem todos formam urólitos de urato, sendo a maioria do sexo masculino. Isso pode ocorrer devido a fatores herdados dispersos na raça que aumentam as chances de alguns animais desenvolverem as concreções. O motivo provável da enfermidade acometer mais os machos são as diferenças anatômicas da uretra, mais curta e larga nas fêmeas, facilitando a eliminação de cálculos pequenos, sem que causem problemas. Fatores ligados ao cromossomo X não foram encontrados (BANNASCH et al., 2004).

Outras raças com frequência acima do normal de ocorrência de cálculos de urato hereditário são Bulldog Inglês e Black Russian Terrier. Cães dessas raças desenvolvedores de urólitos de urato também são homozigotos para o mesmo gene, no entanto, a mutação não ocorre em todos os indivíduos. Dessa forma, os criadores podem realizar testes genéticos para identificar a mutação e eliminar os portadores do gene da reprodução (BANNASCH \& HENTHORN, 2008). Teste genético para a hiperuricosúria está comercialmente disponível e pode ser usado por criadores para a seleção de cruzamentos (BANNASCH et al., 2004; KARMI et al., 2010).

Mutação genética semelhante à canina resulta em defeito tubular associado à formação de urólitos de urato em humanos. Como $100 \%$ de cães da raça Dálmata são homozigotos para o alelo mutante e elimina quantidades aumentadas de ácido úrico na urina, cães da raça são modelo in vivo de estudo para investigar a relação de hiperuricosúria e inibidores de cristalização e para estudo de urolitíase por urato (CARVALHO et al., 2003).

\section{URÓLITOS DE XANTINA}

Urólitos de xantina são raros em cães (OSBORNE et al., 2008; ROGERS et al., 2011), podendo representar aproximadamente $0,1 \%$ de casos de urolitíase 
nessa espécie (OSBORNE et al., 2008). A xantinúria hereditária em humanos é de origem autossômica recessiva e é caracterizada pela excreção urinária de xantina, que é muito pouco solúvel em urina normal, e em menor extensão de hipoxantina. Essa alteração aumenta as chances de desenvolvimento de cálculos de xantina (DANPURE, 2000).

A xantina, que é produzida no metabolismo das purinas, é convertida em ácido úrico pela ação das enzimas xantina oxidase e xantina desidrogenase. Animais com xantinúria hereditária possuem deficiência dessas enzimas, levando à excreção aumentada e acúmulo de xantina, que é pouco solúvel. Dessa forma, pode haver a formação espontânea de urólitos por xantina (KOEHLER et al., 2008). Os urólitos de xantina também podem ser iatrogênicos provocados pelo uso de alopurinol para tratamento de urolitíase por urato ou de leishmaniose (OSBORNE et al., 1995; LING et al., 1997; KOEHLER et al., 2008).

\section{Alterações metabólicas}

A xantina é um produto intermediário do metabolismo das purinas. Como foi dito, decorre da deficiência de xantina oxidase, catalisadora da conversão de hipoxantina em xantina e de xantina em ácido úrico. Em animais acometidos pela deficiência dessa enzima, o ácido úrico encontra-se em concentrações reduzidas no plasma e na urina (LING et al., 1997; HENTHORN et al., 2000). A xantina oxidase é encontrada principalmente no fígado e mucosa intestinal (LING et al., 1997; DANPURE, 2000; HENTHORN et al., 2000; ULRICH et al., 2008). Enfermidades hepáticas podem levar à redução da enzima e à formação de cálculos de xantina (LING et al., 1997).

O alopurinol, fármaco utilizado no tratamento de leishmanioses e urólitos de urato, se liga à xantina oxidase e inibe sua ação. Dessa forma, impede que xantina seja convertida em ácido úrico. Portanto, o uso prolongado desse fármaco, embora evite a formação de urólitos de urato, predispõe à urolitíase por xantina (LING et al., 1997). A conversão de guanina em xantina não é prejudicada, pois não depende de xantina oxidase. A formação de cálculos urinários pode ser rápida, pois a xantina é pouco solúvel na urina, independentemente do $\mathrm{pH}$ (ULRICH et al., 2008).

\section{Alterações hereditárias}

A enzima xantina oxidase é codificada pelo gene $\mathrm{XDH}$. Em humanos, a xantinúria primária está ligada a mutação autossômica recessiva nesse gene e é muito rara (DANPURE, 2000). Em cães, normalmente as concentrações dos metabólitos xantina e hipoxantina, são reduzidas nessa espécie e a xantinúria primária é extremamente incomum. Sua base genética ainda não foi identificada. Embora já tenha sido relatada em Cavalier King Charles Spaniels, os cães dessa raça não parecem mais predispostos que outros ao desenvolvimento de xantinúria hereditária (JACINTO et al., 2013).

\section{URÓLITOS DE SÍLICA}

Urólitos de sílica podem possuir frequência variável de acordo com a localização geográfica. Segundo OSBORNE et al. (1995), por exemplo, representam cerca de $1,2 \%$ dos casos de urolitíase na espécie canina. Já em estudo realizado com urólitos de cães provenientes do Município de Goiânia, a sílica encontrou-se presente em cinco $(9,1 \%)$ das 55 análises realizadas, não sendo encontrados urólitos puros desse componente (ARIZA, 2014). Em determinadas regiões pode inclusive haver há uma alta frequência de urólitos caninos de sílica. Na cidade do 
México, por exemplo, de 105 urólitos analisados, 13,3\% eram formados majoritariamente por sílica. Acredita-se que essa alta proporção seja devido a fatores ambientais locais, mais especificamente à composição da água devido a solo vulcânico (ANGEL-CARAZA et al., 2010).

Ocorrem principalmente em machos, que podem representar mais de $90 \%$ dos casos (KOEHLER et al., 2008). A raça Pastor Alemão é a mais predisposta (OSBORNE et al., 1995). No entanto, também pode ocorrer em animais de outras raças, como Retrievers do Labrador, Shih Tzus, Rottweilers, Boxers, Bichons Frisé (KOEHLER et al., 2008) e Yorkshire Terriers (KOEHLER et al., 2008; ANGELCARAZA et al., 2010). Esse tipo de cálculo não pode ser dissolvido com dieta ou medicamento (OSBORNE et al., 1995).

Cães alimentados com dietas contendo fontes vegetais de proteína estão predispostos a esse tipo de cálculo urinário pois esses alimentos possuem grandes quantidades de ácido silícico. Esses animais eliminam concentrações maiores de sílica na urina (ULRICH et al., 2008), que é altamente insolúvel na urina, especialmente aquela com pH ácido a neutro (KOEHLER et al., 2008).

\section{URÓLITOS DE 2,8-DIIDROXIADENINA}

Urólitos de 2,8-diidroxiadenina (2,8-DHA) são extremamente raros em cães. No entanto, a raça Native American Indian Dog possui tendência ao desenvolvimento desse tipo de cálculo (FURROW et al., 2013).A enzima adenina fosforibosiltransferase (APRT), codificada pelo gene APRT, age como catalizadora na conversão de adenina, que é uma purina, e do 5-fosforibosil-1-pirofosfato em adenosina monofosfato (AMP). A enzima APRT está normalmente distribuída em diversos tecidos (DANPURE, 2000). Na ausência de APRT, a enzima xantina desidrogenase (XDH) converte a adenina em 2,8-DHA, que é altamente insolúvel na urina (BOLLÉE et al., 2010; HOUSTON et al., 2012) e pode precipitar, levando a formação de urólitos (HOUSTON et al., 2012).

Foi identificada mutação no gene APRT em cães acometidos por urólitos

de 2,8-DHA. O alelo mutante c.206A encontra-se presente em estado de homozigose em todos cães afetados, sendo que os animais saudáveis apresentam homozigose para o alelo normal, ou heterozigose pois, como o molde de herança da mutação é autossômico recessivo, o risco de formação de cálculos ocorre apenas em cães homozigóticos para a alteração (FURROW et al., 2013). O mesmo ocorre nos humanos (DANPURE, 2000).

A alteração encontrada no sequenciamento do gene APRT nos cães e humanos afetados é a troca de um aminoácido arginina por outro, a glutamina, na posição 87, o que leva a perda da função do gene, prejudicando o metabolismo da adenina e ocasionando a conversão de adenina em 2,8-DHA (DANPURE, 2000; BOLLÉE et al., 2010). Como essa mutação causa suscetibiliade à urolitíase compartilhada por cães e humanos, a espécie canina é o único modelo de ocorrência natural do problema. Nos cães com mutação do gene APRT, a urolitíase por 2,8-DHA ocorre em animais com no mínimo um ano de idade (FURROW et al., 2013).

\section{ASPECTOS DO DIAGNÓSTICO DA UROLITÍASE}

Os aspectos diagnósticos da urolitíase são importantes para auxiliar na detecção das alterações patológicas e suas causas (DEFOOR et al., 2008; KOEHLER et al., 2008; LULICH \& OSBORNE, 2008). A confirmação de diagnóstico das urolitíase ocorre com a visualização dos cálculos, geralmente realizada por 
exames de imagem, principalmente ultrassonografia e técnicas radiográficas (LULICH \& OSBORNE, 2008). No entanto, o processo diagnóstico não se encerra com a identificação dos cálculos urinários e deve continuar até a identificação dos processos que levaram à formação das concreções em primeiro lugar (KOEHLER et al., 2008; LULICH \& OSBORNE, 2008).

Conhecer os parâmetros laboratoriais dos pacientes com urolitíase é importante para estabelecer o tratamento correto, bem como para identificar aqueles com maior chance de desenvolver recorrências (DEFOOR et al., 2008). A realização de exames de urina e identificação de perfil bioquímico sérico são imprescindíveis na monitoração de pacientes em risco de recorrências e avaliação de pacientes afetados pelas urolitíases. Os padrões urinários podem evidenciar a eliminação de solutos litogênicos e redução de inibidores e os padrões séricos podem indicar a fonte do aumento da excreção dos solutos (LULICH \& OSBORNE, 2008). A diluição da urina previne a formação de cristais urinários e, portanto, nos animais que estão em processo de desenvolvimento de cálculos urinários, a urina se encontra mais concentrada (KOEHLER et al., 2008) e com altas concentrações de solutos que entram na formação dos cálculos urinários (fosfato, magnésio, amônio, cálcio, urato, cistina, xantina, sílica) (LULICH \& OSBORNE, 2008).

As concentrações dos metabólitos na urina de animais que desenvolvem urólitos, no entanto, podem ser muito variáveis (DIJCKER et al., 2015), e a presença de cristais urinários não é indicativo de urolitíase; sua ausência também não exclui a ocorrência de cálculos no trato urinário (KOEHLER et al., 2008). Os mesmos cristais que se desenvolvem in vivo, também podem se desenvolver in vitro e, a refrigeração acelera o processo de formação dos cristais (LULICH \& OSBORNE, 2008). É recomendado que o exame seja realizado, no máximo, 60 minutos após a colheita da amostra (KOEHLER et al., 2008; LULICH \& OSBORNE, 2008) pois, embora a refrigeração preserve grande parte das propriedades físicas e químicas da urina e minimiza o crescimento bacteriano, ela aumenta a formação de cristais (LULICH \& OSBORNE, 2008).

Os cristais que se formam in vivo em urina supersaturada representam um fator de risco para a urolitíase. No entanto, sua presença não significa que existam urólitos formados, nem que estes obrigatoriamente se formarão (LULICH \& OSBORNE, 2008). Os urólitos podem levar a obstruções parciais ou totais, especialmente em machos, ocasionando, além de disúria, hematúria e até mesmo hidronefrose com comprometimento de função renal (OSBORNE et al., 1995; ULRICH et al., 2008). A maioria dos casos de obstrução uretral ocorre nos machos. O estreitamento da uretra na região do osso peniano é frequentemente o local onde se alojam urólitos causando obstruções (SYME, 2012). Outras alterações urinárias que podem estar presentes, independente da composição dos urólitos são a presença de piúria e de hematúria (FALLAHZADEH et al., 2012).

O ideal para a avaliação de solutos urinários, é a medição do perfil urinário em 24 horas para identificar os fatores de risco (DEFOOR et al., 2008). Infelizmente a análise de urina de 24 horas na medicina veterinária é muito difícil de ser realizada. No entanto, ao se corrigir os valores dos analitos a serem identificados pela creatinina, tem-se boa aproximação com os valores de urina de 24 horas (BANNASCH \& HENTHORN, 2008). O pH urinário normal de cães varia entre 5,5 e 7,5 , podendo sofrer leves variações. Como foi dito, $\mathrm{pH}$ urinário influencia na deposição de minerais litogênicos (KOEHLER et al., 2008). A redução da excreção dos diversos inibidores, ou a excreção de isoformas ineficientes das mesmas, também podem estar presentes (CARVALHO et al., 2003). 
Em humanos, a creatinina sérica também age como um importante marcador na urolitíase, pois é um indicador de função renal (SIDOROVA \& GRIGORIEV, 2012). Em cães, a relação entre urolitíase e doença renal crônica é menos óbvia que a relatada em humanos. Isso provavelmente devido à localização vesical dos urólitos contra a localização renal nos humanos e o uso de marcadores de lesão renal é menos sensível na espécie canina (FURROW et al., 2015).

Há ligação entre cálculos urinários e inflamação, não estando claro qual alteração estimula 0 desenvolvimento da outra. Cálculos urinários estão relacionados com cascata de respostas inflamatórias, incluindo a secreção de quimiocinas e níveis urinários aumentados de alguns marcadores inflamatórios como IL-8, interferon-y e IL-6, sendo que pacientes com recorrência apresentam nível ainda maior de IL-8. O aumento de IL-8 urinária pode ser usado como marcador de urolitíase em seres humanos com $90 \%$ de sensibilidade e $68 \%$ de especificidade (SUEN et al., 2010).

Além de análises das características urinárias e séricas, é necessária a avaliação da composição do cálculo urinário, levando em consideração suas camadas de deposição dos minerais (KOEHLER et al., 2008; LULICH \& OSBORNE, 2008; ULRICH et al., 2008), para auxiliar na identificação das possíveis causas da precipitação dos mesmos. Existem técnicas químicas e físicas de análises de urólitos (KOEHLER et al., 2008; LULICH \& OSBORNE, 2008). As químicas se utilizam de reagentes específicos e não permitem a análise da composição de acordo com as camadas (KRAMBECK et al., 2010). As técnicas físicas (difração de raios- $X$, espectroscopia infravermelha, espectroscopia de energia dispersiva, microscopia de luz polarizada e termoanálises) permitem a avaliação em cada região do cálculo urinário, porém, nem todos os compostos presentes são identificados em todas as diferentes técnicas (LEE et al., 2012; PUCETAITE et al., 2012; SELVARAJU et al., 2012). Por esse motivo, é recomendado o uso associado de mais de uma técnica analítica (KOEHLER et al., 2008). De posse das informações acerca da composição do cálculo urinário, das características urinárias e séricas, é possível determinar as causas prováveis do desenvolvimento da urolitíase (LULICH \& OSBORNE, 2008; SIDOROVA \& GRIGORIEV, 2012).

\section{CONSIDERAÇÕES FINAIS}

A urolitíase é uma enfermidade com importância clínica e que possui desenvolvimento extremamente complexo, sendo dependente da ocorrência de diversos fatores endógenos e ambientais, muitas vezes de maneira concomitante, que levam a maior predisposição à precipitação de cristais urinários. Os urólitos podem ser formados por diferentes composições, sendo que cada um dos diferentes tipos possui seus próprios fatores predisponentes. No entanto, a característica primordial para para que haja deposição de cristais litogênicos, independentemente de sua natureza, é o aumento da concentração urinária.

As alterações que levam ao aumento da excreção de solutos urinários podem possuir base genética e, em alguns casos, é possível identificar os genes mutantes presentes permitindo a identificação dos animais com suscetibilidade maior ao desenvolvimento de urolitíase, bem como o afastamento de portadores das mutações detectadas da reprodução. No entanto, muitas vezes os testes genéticos não são realizados. Ainda são poucas as situações nas quais as causas genéticas foram identificadas nos cães e, supõe-se que alterações em mais genes sejam identificadas como possíveis causas ou contribuintes à formação de urólitos nessa espécie. 
A identificação das condições atuantes no metabolismo de um indivíduo que podem levar a alterações de excreção de cristais e ao aumento das chances de formação de cálculos urinários é importante para a detecção correta das causas envolvidas na gênese da urolitíase.

\section{REFERÊNCIAS}

ANGEL-CARAZA, J.; DIEZ-PRIETO I.; PÉREZ-GARCíA, C. C.; GARCÍARODRÍGUEZ, M. B. Composition of lower urinary stones in canines in Mexico City. Urological Research, Berlin,v. 38, n. 3, p. 201-204, 2010.

ARIZA, P. C. Composição de urólitos vesicais de cães determinada por espectroscopia de energia dispersiva (EDS) e análise química. 2014. 51f. Dissertação (Mestrado em Ciência Animal) - Escola de Veterinária e Zootecnia, Universidade Federal de Goiás, 2014.

BANNASCH, D. L.; LING, G. V.; BEA, J.; FAMULA, T. R. Inheritance of urinary calculi in the dalmatian. Journal of Veterinary Internal Medicine, Philadelphia, $v$. 18, n. 4, p. 483-487, 2004.

BANNASCH, D.; HENTHORN, P. S. Changing paradigms in diagnosis of inherited defects associated with urolithiasis. Veterinary Clinics of North America: Small Animal Practice, Philadelphia, v. 39, n. 1, p. 111-125, 2008.

BARTGES, J. W.; CALLENS, A. J. Urolithiasis. Veterinary Clinics of North America: Small Animal Practice, Philadelphia, v. 45, n. 4, p. 747-768, 2015.

BECKNELL, B.; CARPENTER A. R.; BOLON, B; ASPLIN, J. R.; INGRAHAM, S. E.; HAINS, D. S.; SCHWADERER, A. L.; MCHUGH, K. M. Struvite urolithiasis and chronic urinary tract infection in a murine model of urinary diversion. Urology, Ridgewood, v. 81, n. 5, p. 943-948, 2013.

BIBERT, S.; HESS, S. K.; FIRSOV, D.; THORENS, B.; GEERING, K.; HORISBERGER J. D.; BONNY, O. Mouse GLUT9: Evidences for a urate uniporter. American Journal of Physiology. Renal Physiology, Bethesda, v. 297, n. 3, p. F612-F619, 2009.

BODAKHE, K. S.; NAMDEO, K. P.; PATRA, K. C.; MACHWAL, L.; PARETA, S. K. A polyherbal formulation attenuates hyperoxaluria-induced oxidative stress and prevents subsequent deposition of calcium oxalate crystals and renal cell injury in rat kidneys. Chinese Journal of Natural Medicines, Nanjing, v. 11, n. 5, p. 466-471, 2013.

BOLLÉE, G.; DOLLINGER, C.; BOUTAUD, L.; GUILLEMOT, D.; BENSMAN, A.; HARAMBAT, J.; DETEIX, P.; DAUDON, M.; KNEBELMANN, B.; CEBALLOS-PICOT, I. Phenotype and genotype characterization of adenine phosphoribosyltransferase deficiency. Journal of the American Society of Nephrology, Baltimore, v. 21, n. 5, p. 679-688, 2010. 
BRONS, A.-K.; HENTHORN, P. S.; RAJ, K; FITZGERALD, C. A.; LIU, J.; SEWELL, A. C.; GIGER, U. SLC3A1 and SLC7A9 mutations in autosomal recessive or dominant canine cystinuria a new classification system. Journal of Veterinary Internal Medicine, Philadelphia, v. 27, n. 6, p. 1400-1408, 2013.

BUCKLEY C. M.; HAWTHORN, A.; COLYER, A.; STEVENSON, A. E. Effect of dietary water intake on urinary output, specific gravity and relative supersaturation for calcium oxalate and struvite in the cat. British Journal of Nutrition, London, v. 106, n. S1, p. S128-S130, 2011.

CARVALHO, M.; LULICH, J. P.; OSBORNE, C. A.; NAKAGAWA, Y. Role of urinary inhibitors of crystallization in uric acid nephrolithiasis: Dalmatian dog model. Urology, Ridgewood, v. 62, n. 3, 566-570, 2003.

CHILLARÓN, J.; FONT-LLITJÓS, M.; FORT, J.; ZORZANO, A.; GOLDFARB, D. S.; NUNES, V.; PALACÍN, M. Pathophysiology and treatment of cystinuria. Nature Reviews Nephrology, London, v. 6, n. 7, p. 424-434, 2010.

DANPURE, G. J. Genetic disorders and urolithiasis. Urologic Clinics of North America, Philadelphia, v. 27, n. 2, p. 287-299, 2000.

DEFOOR, W.; MINEVICH, E.; JACKSON, E.; REDDY, P.; CLARK, C; SHELDON, C.; ASPLIN, J. Urinary metabolic evaluations in solitary and recurrent stone forming children. Journal of Urology, Baltimore, v. 179, n. 6, p. 2369-2372, 2008.

DIJCKER, J. C.; KUMMELING, A.; HAGEN-PLANTINGA, E. A.; HENDRIKS, W. H. Urinary oxalate and calcium excretion by dogs and cats diagnosed with calcium oxalate urolithiasis. Veterinary Record, London, v. 171, n. 25, p. 646, 2015.

EGGERMANN, T.; VENGHAUS, A.; ZERRES, K. Cystinuria: an inborn cause of urolithiasis. Orphanet Journal of Rare Diseases, London, v.7, p. 19, 2012.

FALLAHZADEH, M. H.; ZARE, J.; AL-HASHEMI, G. H.; DERAKHSHAN, A.; BASIRATNIA, M.; ARASTEH, M. M.; FALLAHZADEH, M. A.; FALLAHZADEH, M.K. Elevated serum levels of vitamin $D$ in infants with urolithiasis. Iranian Journal of Kidney Diseases, v. 6, n. 3, p. 186-191, 2012.

FINLAYSON B. Physicochemical aspects of urolithiasis. Kidney International, New York, v. 13, n. 4, p. 344-360, 1978.

FORTERRE, S; RAILA, J.; KOHN, B.; BRUNNBERG, L.; SCHWEIGERT, F. J. Protein profiling of organic stone matrix and urine from dogs with urolithiasis. Journal of Animal Physiology and Animal Nutrition, Berlin, v.90, n. 5, p. 192-199, 2006.

FURROW, E.; PFEIFER, R. J.; OSBORNE, C. A.; LULICH, J. P. An APRT mutation is strongly associated with and likely causative for 2,8-dihydroxyadenine urolithiasis in dogs. Molecular Genetics and Metabolism, Orlando, v. 111, n.3, p. 399-403, 2013.

FURROW, E.; PATTERSON, E. E.; ARMSTRONG, P. J.; OSBORNE, C. A.; LULICH, J. P. Fasting urinary calcium-to-creatinine and oxalate-to-creatinine ratios in dogs 
with calcium oxalate urolithiasis and breed-matched controls. Journal of Veterinary Internal Medicine, Philadelphia, v. 29, n. 1, p. 113-119, 2015.

GATORIA I. S.; SAINI, N. S.; RAI, T. S.; DWIVEDI, P. N. Comparison of three techniques for the diagnosis of urinary tract infections in dogs with urolithiasis. Journal of Small Animal Practice, Oxford, v. 47, n. 12, p. 727-732, 2006.

HENTHORN, P. S.; LIU, J.; GIDALEVICH, T.; FANG, J.; CASAL, M. J.; PATTERSON, D. F.; GIGER, U. Canine cystinuria: Polymorphism in the canine SLC3A1 gene and identification of a nonsense mutation in cystinuric Newfoundland dogs. Human Genetics, Berlin, v. 107, n. 4, p. 295-303, 2000.

HESS, B.; HASLER-STRUB, U.; ACKERMANN, D.; JAEGER, P. Metabolic evaluation of patients with recurrent idiopathic calcium nephrolithiasis. Nephrology Dialysis Transplantation, Oxford, v. 12, n. 7, p. 1362-1368, 1997.

HOPPE, A.; DENNEBERG, T.; JEPPSON, J. O.; KAGEDAL, B. Canine cystinuria: an extended study on the effects of 2-mercaptopropionylglycine on cysteine urolithiasis and urinary cistine excretion. British Veterinary Journal, London, v. 149, n. 3, p. 235-251, 1993a

HOPPE, A.; DENNEBERG, T.; JEPPSON, J. O.; KAGEDAL, B. Urinary excretion of amino acids in normal and cystinuric dogs. British Veterinary Journal, London, $v$. 149 , n. 3, p. 253-268, 1993b.

HOUSTON, D. M.; MOORE, A. E.; MENDONÇA, S. Z.; TAYLOR, J. A. 2,8dihydroxyadenine uroliths in a dog. Journal of the American Veterinary Medical Association, Chicago, v. 241, n. 12, p. 1348-1352, 2012.

JACINTO, A. M. L.; MELLANBY, R. J.; CHANDLER, M.; BOMMER, N. X.; CARRUTHERS, H.; FAIRBANKS, L. D. GOW, A. G. Urine concentrations of xanthine, hypoxanthine and uric acid in UK Cavalier King Charles spaniels. Journal of Small Animal Practice, Oxford, v. 53, n. 8, p. 395-398, 2013.

KARMI, N.; BROWN, E. A.; HUGHES, S. S.; MCLAUGHLIN, B.; MELLERSH, C. S.; BIOURGE, V.; BANNASCH, D. L. Estimated frequency of the canine hyperuricosuria mutation in different dog breeds. Journal of Veterinary Internal Medicine, Philadelphia, v. 24, n. 6, p. 1337-1342, 2012

KIM, J.-Y.; KIM, Y.-S.; JANG, I.-H.; JUNG, J.-D.; KIM, T.-H.; KIM, H.-R. Interleukin$1 \beta$, calcium-sensing receptor, and urokinase gene polymorphisms in Korean patients with urolithiasis. Korean Journal of Urology, v. 52, n. 5, p. 340-344, 2011a

KIM, J.; CHOI, H.; LEE, Y.; JUNG, J.; YEON, S.; LEE, H.; LEE, H. Multicystic dysplastic kidney disease in a dog. Canadian Veterinary Journal, Ottawa, v. 52, n. 6, p. 645- 649, 2011 b.

KOEHLER, L. A.; OSBORNE, C. A.; BUETTNER, M. T.; LULICH, J. P.; BEHNKE, R. Canine urolithiasis: Frequently asked questions and their answers. Veterinary Clinics of North America: Small Animal Practice, Philadelphia, v. 39, n. 1, p. 161$181,2008$. 
KRAMBECK, A. E.; KHAN, N. F.; JACKSON, M. E.; LINGEMAN, J. E.; MCATEER, J. A.; WILLIAMS, J. C. Jr. Innaccurate reporting of mineral composition by comercial stone analysis laboratories: implications for infection and metabolics stones. Journal of Urology, Baltimore, v. 184, n. 4, p. 1543-1549,. 2010.

LEE, H. P.; LEONG, D.; HENG, C. T. Characterization of kidney stones using the thermogravimetric analysis with electron dispersive spectroscopy. Urological Research, Berlin, v. 40 n.32, p. 197-204, 2012.

LING, G. V.; CASE, L. C.; NELSON, H.; HARROLD, D. R.; JOHNSON, D. L.; VULLIET, P. R. Pharmacokinetics of allopurinol in Dalmatian dogs. Journal of Veterinary Pharmacology and Therapeutics, Oxford, v. 20, n. 2, p. 134-138, 1997.

LULICH, J. P.; OSBORNE, C. A. Changing paradigms in the diagnosis of urolithiasis Veterinary Clinics of North America: Small Animal Practice, v. 39, n. 1, p. 79-91, 2008.

NATH, R.; THIND, S. K.; MURTHY, M. S.; TALWAR, H. S.; FAROOQUI, S. Molecular aspects of idiopathic urolithiasis. Molecular Aspects of Medicine, Elmsford, v. 1, n. 1, p. 1-176, 1984.

NEUHAUS, T. J.; BELZER, T.; BLAU, N.; HOPPE, B.; SIDHU, H.; LEUMANN, E. Urinary oxalate excretion in urolithiasis and nephrocalcinosis. Archives of Diseases in Childhood, London, v. 82, n. 4, p. 822-826, 2000.

OKAFOR, C. C.; LEFEBVRE, S. L.; PEARL, D. L.; YANG, M.; WANG, M.; BLOIS, S. L.; LUND, E. M.; DEWEY, C. E. Risk factors associated with calcium oxalate urolithiasis in dogs evaluated at general care veterinary hospitals in the United States. Preventive Veterinary Medicine, Amsterdam, v. 115, n. 4, p. 217-227, 2014.

OKUMURA, N.; TSUJIHATA, M.; MOMOHARA, C.; YOSHIOKA, I.; SUTO, K.; NONOMURA, N.; OKUYAMA, A.; TAKAO, T. Diversity in proteins profiles of individual calcium oxalate kidney stones. PIoS ONE [on line], 9 p., 2013. Disponível em: $\quad$ http://journals.plos.org/plosone/article?id=10.1371/journal.pone.0068624> Acesso em: 18 jul. 2015.

OMBRA, M. N.; CASULA, S.; BIINO, G.; MAESTRALE, G.;CARDIA, F.; MELIS, P.; PIRASTU, M. Urinary glycosaminoglycans as risk factors for uric acid nephrolithiasis: Case control study in a sardinian genetic isolate. Urology, Ridgewood, v. 62, n. 3, p. 416-420, 2003.

OSBORNE, C. A.; LULICH, J. P.; BARTGES, J. W.; UNGER, L. K.; THUMCHAI, R.; KOEHLER, L. A.; BIRD, K. A.; FELICE L. J. Canine and feline urolithiasis: relationship of etiopathogenesis to treatment and prevention. In: Osborne, C. A.; Finco, D. R. Canine and feline nephrology and urology. Philadelphia: Lippincott Williams \& Wilkins, 1995. p. 798-888.

OSBORNE, C. A.; LULICH, J. P.; KRUGER, J. M.; ULRICH, L. K.; KOEHLER, L. A. Analysis of 451,891 canine uroliths, feline uroliths, and feline urethral plugs from 1981 to 2007: Perspectives from the Minnesota Urolith Center. Veterinary Clinics of North America: Small Animal Practice. Philadelphia, v. 39, n. 1, p. 183-197, 2008. 
PAK, C. Y. C.; WATERS, O.; ARNOLD, L.; HOLT, K.; COX, C.; BARILLA, D. Mechanism for calcium urolithiasis among patients with hyperuricosuria: Supersaturation of urine with respect to monosodium urate. Journal of Clinical Investigation, New York, v. 59, n. 3, p. 426- 431, 1976.

PICUT, C. A.; LEWIS, R. M. Comparative pathology of canine hereditary nephropathies: an interpretative review. Veterinary Research Communications, Dordrecht, v. 11, n. 6, p. 561-581, 1987.

PUCETAITE, M.; HENDRIXSON, V.; ZELVYS, A.; JANKEVICIUS, F.; TYLA, R.; CEPONKUS, J.; SABLINSKAS, V. Application of infrared spectroscopic imaging in specular reflection mode for determination of distribution of chemical components in urinary stones. Journal of Molecular Structure, Amsterdam, v. 1031, n. 1, p. 38-42, 2012.

PUTTICK, J. L.; SEREDA, C. W. Suture-related urolithiasis following repair of inadvertent prostatectomy in a dog Canadian Veterinary Journal, Ottawa, v. 53, n. 7, p. 787- 790, 2012.

RAILA, J.; FORTERRE, S.; SCHWEIGERT, F. J. Levels of retinol and retinyl esters in plasma and urine of dogs with urolithiasis. Journal of Veterinary Medicine Series A, Berlin, v. 50, n. 7, p. 380-382, 2003.

ROBERTSON, W. G.; JONES, J. S.; HEATON, M. A.; STEVENSON, A. E.; MARKWELL, P. J. Predicting the crystallization potential of urine from cats and dogs with respect to calcium oxalate and magnesium ammonium phosphate (struvite). Journal of Nutrition, Philadelphia, v. 132, n. 6, p. 1637S-1641S, 2002.

ROGERS, K. D.; JONES, B.; ROBERTS, L.; RICH, M.; MONTALTO, N.; BECKETT, $\mathrm{S}$. Composition of uroliths in small domestic animals in the United Kingdom. Veterinary Journal, London, v. 188, n. 2, p. 228-230, 2011.

SANDERSON, S. L.; OSBORNE, C. A.; LULICH, J. P.; BARTGES, J. W.; PIERPONT, M. E.; OGBURN, P. N.; KOEHLER, L. A.; SWANSON, L. L.; BIRD, K. A.; ULRICH, L. K. Evaluation of urinary carnitine and taurine excretion in 5 cystinuric dogs with carnitine and taurine deficiency. Journal of Veterinary Internal Medicine, Philadelphia, v. 15, n. 2, p. 94-100, 2001.

SELVARAJU, R.; THIRUPPATHI, G.; RAJA, A. FT-IR spectral studies on certain human urinary stones in the patients of rural area. Spectrochimica Acta Part A Molecular And Biomolecular Spectroscopy, Kidlington, v. 93, n. 4, p. 260- 265, 2012.

SIDOROVA, A. A.; GRIGORIEV, A. V. Determination of diagnostical markers of urolithiasis by capillary electrophoresis. Journal of Analytical Chemistry, New York, v. 67, n. 5 , p. $478-485,2012$.

STEJSKAL, D.; KARPISEK, M.; VRTAL, R.; STUDENT, V.; SOLICHOVA, P.; FIALA, R.; STEJSKAL, P. Urine fetuin-A values in relation to the presence of urolithiasis. BJU International, Edinburgh, v. 101, n. 9, p. 1151-1154, 2008. 
SUEN, J. L.; LIU, C. C.; LIN, Y. S.; TSAI, Y. F.; JUO, S. H.; CHOU, Y. H. Urinary chemokinescytokines are elevated in patients with urolithiasis. Urological Research, Berlin, v. 38, n. 2, p. 81-87, 2010.

SYME, H. M. Stones in cats and dogs: What can be learnt from them? Arab Journal of Urology, v. 10, n. 3, p. 230-239, 2012.

TAN, Y.K.; CHA, D. Y.; GUPTA. M. Management of stones in abnormal situations. Urologic Clinics of North America, Philadelphia, v. 40, n. 1, p. 79-97, 2013.

THAMILSEVAN, V.; MENON, M.; THAMILSEVAN, S. Oxalate at physiological urine concentrations induces oxidative injury in renal epithelial cells effect of alphatocopherol and ascorbic acid. BJU International, Edinburgh, v. 114, n. 1, p. 140-150, 2014.

ULRICH, L. K.; OSBORNE, C. A.; COKLEY, A.; LULICH, J. P. Changing paradigms in the frequency and management of canine compound uroliths. Veterinary Clinics of North America: Small Animal Practice, Philadelphia, v. 39, n. 3, p. 41-53, 2008.

VRABELOVA, D.; SILVESTRINI, P.; CIUDAD, J.; GIMENEZ, J. C.; BALLESTEROS, M.; PUIG, P.; COPEGUI, R. R. Analysis of 2735 canine uroliths in Spain and Portugal. A retrospective study: 2004-2006. Research in Veterinary Science, London, v. 91, n.2, p. 208-211, 2011.

YOON HY.; MANN, F. A.; PUNKE, J. P.; JEONG, S. W. Bilateral ureteral ectopia with renal dysplasia and urolithiasis in a dog. Journal of the American Animal Hospital Association, South Bend, v. 46, n. 3, p. 210-214, 2012. 